\title{
A Review of Recent Landmark Trials in Glaucoma
}

Eileen Choudhury and Joseph Panarelli

New York Eye and Ear Infirmary of Mount Sinai, New York, NY, USA

$\mathrm{R}$ ecent research has focused on surgical treatment of glaucoma since it offers a better control of intraocular pressure (IOP) than medical treatment. Clinical studies have aimed to improve the outcomes of established techniques, such as trabeculectomy and glaucoma drainage devices. In addition, minimally invasive glaucoma surgery has become increasingly popular over the past 5 years, providing improved safety as well as mild-to-moderate IOP lowering.

DOl: https://doi.org/10.17925/USOR.2019.12.1.28

\section{Keywords}

Landmark trials, minimally

invasive glaucoma surgery

Disclosures: Eileen Choudhury has no relevant financial disclosures to declare. Joseph Panarelli has the following disclosures: Allergan, Santen, Glaukos, New World Medical, Aerie.

Review Process: Double-blind peer review.

Compliance with Ethics: This study involves a review of the literature and did not involve any studies with human or animal subjects performed by any of the authors.

Authorship: The named authors meet the Internationa Committee of Medical Journal Editors (ICMJE) criteria for authorship of this manuscript, take responsibility for the integrity of the work as a whole, and have given final approval for the version to be published.

Received: January 23, 2019

Accepted: March 29, 2019

Citation: US Ophthalmic Review. 2019;12(1):28-32

Corresponding Author: Joseph Panarelli, 222 E 41st Street, New York, NY 10017, USA.

E: joseph.panarelli@nyulangone.org

Support: No funding was received in

the publication of this article.
In recent years, the field of clinical glaucoma research has been geared towards investigating surgical intervention. Recent trials have focused on examining the outcomes of conventional glaucoma surgery, including trabeculectomy and glaucoma drainage devices. They have additionally explored the novel uses of minimally invasive glaucoma devices.

This review presents an update on recent landmark glaucoma trials that we feel have been significant in guiding the surgical management and treatment of glaucoma. The trials chosen for review include randomized, prospective surgical trials in glaucoma published during the last 5 years. Also included are retrospective or noncomparative pivotal studies of newer devices, also published within the last 5 years. A brief summary of these trials has been included for reference in Table 1.

\section{Tube versus Trabeculectomy (TVT) study ${ }^{1}$}

This multicenter randomized clinical trial compared the safety and efficacy of tube shunt surgery to trabeculectomy with mitomycin-C in eyes with previous cataract extraction and intraocular lens implantation and/or failed glaucoma surgery. A total of 212 eyes from 212 patients were enrolled, with 107 in the tube group and 105 in the trabeculectomy group. Patients in the tube group underwent placement of a Baerveldt-350 $\mathrm{mm}^{2}$ glaucoma drainage implant superotemporally with complete restriction of flow at the time of implantation. Patients in the trabeculectomy group had a superior trabeculectomy with application of $0.4 \mathrm{mg} / \mathrm{mL}$ of mitomycin-C for 4 minutes. Outcome measures included intraocular pressure (IOP), visual acuity, use of adjunctive medical therapy, surgical complications, visual fields, quality of life, and failure. Failure was defined as IOP $>21 \mathrm{mmHg}$ or not reduced by $20 \%$ below baseline, IOP $\leq 5 \mathrm{mmHg}$, reoperation for glaucoma, or loss of light perception vision.

\section{Key findings}

Tube shunt and trabeculectomy both produced a significant and sustained reduction in IOP. At 5 years, IOP was $14.4 \pm 6.9 \mathrm{mmHg}$ in the tube group and $12.6 \pm 5.9 \mathrm{mmHg}$ in the trabeculectomy group ( $p=0.12$ ). Of patients in the tube group, 63.9\% maintained an IOP $\leq 14 \mathrm{mmHg}$ at 5 years, compared to $63.5 \%$ of patients in the trabeculectomy group ( $p>0.99)$. A significantly greater use of adjunctive medical therapy was observed in the tube group compared with the trabeculectomy group during the first 2 postoperative years; however, this difference was not observed at 3 years and all subsequent study visits. The tube group had a higher overall success rate after 5 years. Treatment failure occurred in $32.8 \%$ of patients in the tube group and $50.0 \%$ of patients in the trabeculectomy group at 5 years $(p=0.034)$. The most common cause for failure during 5 years of follow-up in both treatment groups was inadequate IOP reduction. There was no significant difference in visual acuity between the tube and trabeculectomy groups at 5 years.

\section{Study limitations}

The study population was limited to patients who had undergone previous incisional surgery, therefore study results cannot be generalized to dissimilar patient groups. All study patients randomized to the tube group received a Baerveldt-350 $\mathrm{mm}^{2}$ glaucoma drainage implant, so study 
results cannot be generalized to different implant types. One subgroup of patients had a history of previous trabeculectomy with mitomycin- $\mathrm{C}$, and thereby had already failed one treatment arm. This subgroup of patients may have introduced bias in favor of the tube group. Finally, the patient and clinician were not masked to the randomized treatment assignment, which may introduce a source of bias.

\section{Bottom line}

The results of the TVT study support the expanding use of tube shunt surgery in the management of not only refractory glaucomas but also eyes at lower risk for failure. However, this study does not show either tube shunt or trabeculectomy to be clearly superior to the other. Factors such as surgeon skill, patient-specific considerations, and patient expectations must be considered when selecting the ideal surgical procedure.

\section{Primary Tube versus Trabeculectomy (pTVT) study ${ }^{2}$} This multicenter, randomized clinical trial compared the safety and efficacy of tube shunt surgery to trabeculectomy with mitomycin-C in eyes with no previous incisional surgery. A total of 242 eyes from 242 patients were enrolled, with 125 patients in the tube group and 117 patients in the trabeculectomy group. Patients in the tube group underwent placement of a Baerveldt-350 $\mathrm{mm}^{2}$ glaucoma drainage implant. Patients in the trabeculectomy group had a superior trabeculectomy with application of $0.4 \mathrm{mg} / \mathrm{mL}$ of mitomycin-C for 2 minutes. The primary outcome measure was the cumulative rate of surgical failure at 1 year. Failure was defined as IOP $>21 \mathrm{mmHg}$ or not reduced by $20 \%$ below baseline, IOP $\leq 5 \mathrm{mmHg}$, reoperation for glaucoma, or loss of light perception vision. Certain patients were randomized but did not receive surgical treatment, while others exited the study for other reasons. At 1 year, 117 patients in the tube group and 109 patients in the trabeculectomy group were included in the analysis of outcomes.

\section{Key findings}

Treatment failure occurred in 23 patients (19.6\%) in the tube group and in nine patients (8.2\%) in the trabeculectomy group at 1 year $(p=0.02)$. The cumulative probability of failure was $17.3 \%$ in the tube group and $7.9 \%$ in the trabeculectomy group at 1 year $(p=0.01)$. The rate of complete success was significantly higher in the trabeculectomy group relative to the tube group $(p<0.001)$. Inadequate IOP reduction was the most common cause for failure during the first year of follow-up in both treatment groups; however, both surgical procedures produced a significant and sustained reduction in IOP. Placement of a tube produced a 37.5\% reduction in IOP, and trabeculectomy with mitomycin-C achieved a $46.0 \%$ decrease in IOP at 1 year of follow-up. The degree of IOP reduction was significantly greater in the trabeculectomy group compared with the tube group at 1 year. Mean IOP was $13.8 \pm 4.1 \mathrm{mmHg}$ in the tube group and $12.4 \pm 4.4 \mathrm{mmHg}$ in the trabeculectomy group. Mean reduction from baseline was $9.3 \pm 6.6 \mathrm{mmHg}$ in the tube group and $11.4 \pm 6.6 \mathrm{mmHg}$ in the trabeculectomy group $(p=0.02)$.

Significantly greater use of glaucoma medical therapy was observed in the tube group compared with the trabeculectomy group during the first year of study, though a significant reduction in the use of medical therapy was actually seen in both treatment groups. The rate of reoperation for glaucoma was similar in both treatment groups, and there were no significant differences in visual acuity between the tube and trabeculectomy groups at 1 year of follow-up. The overall incidence of intraoperative complications was similar between the tube and trabeculectomy groups. Early postoperative complications developing within the first post-operative month occurred with significantly greater frequency in the trabeculectomy group compared with the tube group, reported in $19.6 \%$ of patients in the tube group and $33.3 \%$ in the trabeculectomy group $(\mathrm{p}=0.03)$.

\section{Study limitations}

The limitations of the PTVT study are similar to those of the TVT study, excepting the exclusion of patients with previous failed trabeculectomy in PTVT.

\section{Bottom line}

Patients who underwenttube shuntsurgery had a higher failure rate compared with those who underwent trabeculectomy with mitomycin-C during the first year of follow-up in this study. Inadequate IOP reduction was the most common reason for failure in both treatment groups. While trabeculectomy may be a more effective primary surgery, a better safety profile may favor tube shunt surgery. More definitive conclusions can be made when the 3- and 5-year follow-up data become available.

\section{Randomized, Prospective, Comparative Trial of EX-PRESS Glaucoma Filtration Device versus Trabeculectomy (XVT) study ${ }^{3}$}

The EX-PRESS ${ }^{\circledast}$ Mini-Glaucoma Shunt (Alcon Laboratories, Fort Worth, TX, USA) is a non-valved stainless steel device that shunts fluid from the anterior chamber to the subconjunctival space in a manner similar to a standard trabeculectomy. This biocompatible/magnetic resonance image (MRI) compatible device has a 50-micron lumen and an external diameter of 400 microns which enables it to restrict flow.

The XVT study, conducted by Netland et al., was a randomized, prospective, comparative trial of the EX-PRESS placed under a partial-thickness scleral flap versus standard trabeculectomy alone. This study included 120 eyes from 120 patients. All patients were treated intraoperatively with mitomycin-C and observed postoperatively for 2 years. Surgical success was defined as IOP between 5 to $18 \mathrm{mmHg}$, with or without medications, and without further glaucoma surgery.

\section{Key findings}

At 2 years, the mean IOP was significantly reduced compared with baseline in both groups $(p<0.001)$. Mean IOP was $14.7 \pm 4.6 \mathrm{mmHg}$ and $14.6 \pm 7.1 \mathrm{mmHg}$ in the EX-PRESS and trabeculectomy groups, respectively $(p=0.927)$. The success rate was $83 \%$ and $79 \%$ in the EX-PRESS and trabeculectomy groups, respectively $(p=0.563)$. Visual acuity was significantly decreased on postoperative day 1 in both groups, but it did not differ significantly compared with baseline at month 1 after EX-PRESS implantation ( $p=0.285$ ) and month 3 after trabeculectomy $(p=0.255)$. The median time for return to baseline visual acuity was 0.7 months in the EX-PRESS group and 2.2 months in the trabeculectomy group. The total number of postoperative complications was higher after trabeculectomy than after EX-PRESS implantation ( $p=0.013)$, and there was one case of endophthalmitis in the trabeculectomy group.

\section{Study limitations}

The patient and clinician were not masked to the randomization of treatment assignment, which could have introduced bias. 
Table 1: Summary of trials reviewed

\begin{tabular}{|c|c|c|c|c|}
\hline Trial & Study groups & Primary outcome measures & Results & Conclusion \\
\hline TVT $^{1}$ & $\begin{array}{l}\text { Tube shunt surgery versus } \\
\text { trabeculectomy }\end{array}$ & $\begin{array}{l}\text { IOP, visual acuity, use of } \\
\text { supplemental medical therapy, } \\
\text { and failure }\end{array}$ & $\begin{array}{l}\text { 1. Both groups experienced significant and } \\
\text { sustained reduction in IOP } \\
\text { 2. Greater use of adjunctive medicine in tube shunt } \\
\text { group during first } 2 \text { postoperative years }\end{array}$ & $\begin{array}{l}\text { Supports expanding use of tube } \\
\text { shunt surgery, but does not } \\
\text { show either procedure to be } \\
\text { superior to the other }\end{array}$ \\
\hline pTVT $^{2}$ & $\begin{array}{l}\text { Tube shunt surgery versus } \\
\text { trabeculectomy (in patients } \\
\text { with no previous incisional } \\
\text { surgery) }\end{array}$ & $\begin{array}{l}\text { Cumulative rate of surgical failure } \\
\text { at } 1 \text { year }\end{array}$ & $\begin{array}{l}\text { 1. Cumulative probability of failure was } 17.3 \% \text { in } \\
\text { tube group and } 7.9 \% \text { in trabeculectomy group } \\
\text { 2. Rate of complete success higher in the } \\
\text { trabeculectomy group } \\
\text { 3. Degree of IOP reduction greater in } \\
\text { trabeculectomy group }\end{array}$ & $\begin{array}{l}\text { Tube shunt surgery had a higher } \\
\text { failure rate compared with } \\
\text { trabeculectomy at } 1 \text { year of } \\
\text { follow-up }\end{array}$ \\
\hline $\mathrm{XVT}{ }^{3}$ & $\begin{array}{l}\text { EX-PRESS }{ }^{\circledast} \text { Mini-Glaucoma } \\
\text { Shunt versus } \\
\text { trabeculectomy (control) }\end{array}$ & $\begin{array}{l}\text { Mean IOP, medication reduction, } \\
\text { surgical success }\end{array}$ & $\begin{array}{l}\text { 1. IOP significantly reduced from baseline in both } \\
\text { groups } \\
\text { 2. Success rate } 83 \% \text { in EX-PRESS group and } 79 \% \\
\text { in trabeculectomy group }\end{array}$ & $\begin{array}{l}\text { Both procedures produced IOP } \\
\text { reduction and had similar rates } \\
\text { of success }\end{array}$ \\
\hline COMPASS $^{4}$ & $\begin{array}{l}\text { CyPass }^{\circledast} \text { Micro-Stent + } \\
\text { phacoemulsification versus } \\
\text { phacoemulsification alone } \\
\text { (control) }\end{array}$ & $\begin{array}{l}\text { Percentage of patients achieving } \\
\geq 20 \% \text { unmedicated diurnal IOP } \\
\text { lowering from baseline, mean IOP } \\
\text { change, glaucoma medication use, } \\
\text { ocular adverse event incidence }\end{array}$ & $\begin{array}{l}\text { 1. Mean IOP reduction was } 7.4 \mathrm{mmHg} \text { in treatment } \\
\text { group versus } 5.4 \mathrm{mmHg} \text { in control group } \\
\text { 2. Mean medication use in controls decreased to } \\
0.6 \pm 0.8 \text { medications and in treatment group } \\
\text { decreased to } 0.2 \pm 0.6 \text { medications }\end{array}$ & $\begin{array}{l}\text { Combining CyPass Micro-Stent } \\
\text { with cataract surgery can } \\
\text { effectively lower IOP and } \\
\text { glaucoma medication use in } \\
\text { patients }\end{array}$ \\
\hline HYDRUS $\|^{5}$ & $\begin{array}{l}\text { Hydrus }^{\circledast} \text { Microstent }+ \\
\text { phacoemulsification versus } \\
\text { phacoemulsification alone } \\
\text { (control) }\end{array}$ & $\begin{array}{l}\geq 20 \% \text { decrease in washed out } \\
\text { diurnal IOP, mean diurnal IOP, } \\
\text { proportion of patients requiring } \\
\text { medications, mean number of } \\
\text { medications }\end{array}$ & $\begin{array}{l}\text { 1. } 73 \% \text { of patients in treatment group were } \\
\text { medication free compared to } 38 \% \text { in control } \\
\text { group } \\
\text { 2. } 80 \% \text { of patients in treatment group achieved } \\
\geq 20 \% \text { IOP lowering compared to } 46 \% \text { in } \\
\text { treatment group } \\
\text { 3. Significant increase in rate of peripheral anterior } \\
\text { synechiae in treatment group }\end{array}$ & $\begin{array}{l}\text { Hydrus Microstent combined } \\
\text { with phacoemulsification offers } \\
\text { reduction in IOP and adjunctive } \\
\text { medication use compared with } \\
\text { phacoemulsification alone }\end{array}$ \\
\hline XEN $^{6}$ & XEN ${ }^{\circledast}$ Gel Stent & $\begin{array}{l}\text { Percentage of patients achieving } \\
\geq 20 \% \text { IOP lowering from baseline } \\
\text { on same or fewer medications, } \\
\text { mean IOP change from baseline, } \\
\text { procedure related adverse events }\end{array}$ & $\begin{array}{l}\text { 1. } 76.3 \% \text { of patients achieved } \geq 20 \% \text { IOP lowering } \\
\text { from baseline on same or fewer medications } \\
\text { 2. Mean IOP reduction from baseline was } \\
6.4 \pm 1.1 \mathrm{mmHg} \\
\text { 3. Mean number of medications decreased from } \\
3.5 \pm 1.0 \text { to } 1.7 \pm 1.5\end{array}$ & $\begin{array}{l}\text { XEN Gel Stent offers reduction in } \\
\text { IOP and adjunctive medication } \\
\text { use in patients with refractory } \\
\text { glaucoma }\end{array}$ \\
\hline GATT & GATT & $\begin{array}{l}\text { IOP, number of glaucoma } \\
\text { medications, visual acuity, } \\
\text { intraoperative and postoperative } \\
\text { medications }\end{array}$ & $\begin{array}{l}\text { 1. } 57 \text { patients with POAG experienced mean IOP } \\
\text { decrease of } 7.7 \mathrm{mmHg} \\
\text { 2. } 28 \text { patients with secondary glaucoma } \\
\text { experienced mean IOP decrease of } 17.2 \mathrm{mmHg}\end{array}$ & $\begin{array}{l}\text { Minimally invasive approach } \\
\text { of the GATT procedure can, in } \\
\text { certain patients, offer significant } \\
\text { IOP lowering and reduction of } \\
\text { adjunctive medication use }\end{array}$ \\
\hline
\end{tabular}

GATT = gonioscopy-assisted trans/uminal trabeculotomy; IOP = intraocular pressure; $P O A G$ = primary open-angle glaucoma; PTVT = Primary Tube versus Trabeculectomy Study; TVT = Tube versus Trabeculectomy Study; XVT = Randomized, Prospective, Comparative Trial of EX-PRESS Glaucoma Filtration Device versus Trabeculectomy Study.

\section{Bottom line}

A major theoretical advantage of the EX-PRESS is that it is a safer alternative to standard trabeculectomy. The XVT investigators found that patients undergoing filtration surgery with the EX-PRESS had fewer total complications and a faster rate of visual recovery compared to trabeculectomy. A large number of the complications in the trabeculectomy group were resolved with conservative management, and any serious, vision-threatening complications were uncommon in both treatment groups. Both procedures produced a significant and sustained reduction in IOP and had similar rates of success.

\section{COMPASS trial ${ }^{4}$}

The CyPass $^{\circledR}$ Micro-Stent (Alcon Laboratories, Fort Worth, TX, USA) is a $6.35 \mathrm{~mm}$ fenestrated, flexible microstent with a $300 \mu \mathrm{m}$ luminal diameter that is inserted into the supraciliary space. It is designed to increase aqueous outflow from the anterior chamber into the supraciliary space via the uveoscleral outflow pathway.

This multicenter, randomized clinical trial evaluated the safety and efficacy of the CyPass Micro-Stent for treating patients with mild-to-moderate primary open-angle glaucoma (POAG) who were simultaneously undergoing cataract surgery. Of 505 subjects, 131 patients were intraoperatively randomized into a phacoemulsification-only (control) group, and 374 were randomized to a phacoemulsification with supraciliary microstenting (treatment) group. Outcome measures included percentage of patients achieving $\geq 20 \%$ unmedicated diurnal IOP lowering versus baseline, mean IOP change and adjunctive glaucoma medication use, and ocular adverse event incidence through 24 months. 


\section{Key findings}

Sixty percent of patients in the control group versus $77 \%$ of patients in the treatment group achieved $\geq 20 \%$ unmedicated IOP lowering from baseline at 24 months $(p=0.001)$. Mean IOP reduction was $7.4 \mathrm{mmHg}$ for the treatment group versus $5.4 \mathrm{mmHg}$ in controls $(p<0.001)$ Fifty-nine percent of control patients versus $85 \%$ of treatment subjects were medication-free at 24 months. Mean medication use in controls decreased to $0.6 \pm 0.8$ medications, while mean medication use in the treatment group decreased to $0.2 \pm 0.6$ medications at 24 months $(p<0.001)$. No vision-threatening adverse events related to microstents occurred. There were eight stent obstructions (2.1\%), two instances of stent malpositioning, and two instances of stent migration or dislodgement. Stent obstructions were related to the formatin of focal peripheral anterior synechiae. Fewer than 98\% of all subjects achieved 20/40 best-corrected visual acuity or better.

\section{Study limitations}

The principal investigator at each study site was not masked to treatment randomization during patient follow-up examinations, which may be a source of bias. The Latino/Hispanic ethnicity category may be underrepresented in this study.

\section{Bottom line}

Combining the CyPass Micro-Stent with cataract surgery offers a means to effectively lower IOP and glaucoma medication use in patients with mild-to-moderate POAG and comorbid cataracts. However, analysis of the COMPASS data at 5 years has shown significantly greater central endothelial cell loss in the treatment group compared with the control group. ${ }^{5}$ This may be related to the device's position in the anterior chamber, change in aqueous flow, device migration, or a number of other variables. In response, Alcon has at this time voluntarily withdrawn the CyPass Micro-Stent from the market.

\section{HYDRUS II trial ${ }^{6}$}

The Hydrus ${ }^{\circledR}$ Microstent (Ivantis, Inc., Irvine, CA, USA) is an $8 \mathrm{~mm}$ long device made of nitinol designed for ab interno placement through the trabecular meshwork into Schlemm's canal. The length of the stent dilates and scaffolds a quadrant of Schlemm's canal, providing access to multiple collector channels.

This prospective, multicenter, single-masked, randomized clinical trial was designed to evaluate the safety and efficacy of the Hydrus Microstent in lowering IOP in patients with open-angle glaucoma undergoing simultaneous cataract surgery. A total of 100 eyes were included, with 50 eyes randomized to the microstent combined with phacoemulsification (treatment) group and 50 patients randomized to the phacoemulsification-only (control) group. Main outcome measures included $\geq 20 \%$ IOP lowering in washed out diurnal IOP at 12 and 24 months of follow-up compared with baseline. The proportion of patients requiring medications at follow-up and the mean number of medications were also analyzed.

\section{Key findings}

At 2 years, $73 \%$ of patients in the treatment group were medication-free compared to $38 \%$ of patients in the control group ( $p=0.0008$ ). At 2 years, following medication removal, $80 \%$ of the patients in the treatment group achieved $\geq 20 \%$ IOP lowering compared to $46 \%$ of patients in the control group $(p=0.0008)$. Washed out mean diurnal IOP was $16.9 \pm 3.3 \mathrm{mmHg}$ in the treatment group compared to $19.2 \pm 4.7 \mathrm{mmHg}$ in the control group ( $p=0.0093$ ). There was no difference in follow-up visual acuity between groups. There was a significant increase in the rate of peripheral anterior synechiae formation in the treatment group compared to the control group at 2 years of follow-up ( $p=0.0077$ ). Otherwise, there were no significant differences in rate of adverse events between the two groups.

\section{Study limitations}

The patient and clinician were not masked to the randomization of treatment assignment. This study was conducted in a white population in a small number of centers, and study results may not be generalizable to a larger population.

\section{Bottom line}

This study is the first report in a multicenter, randomized trial on the effect of phacoemulsification in open-angle glaucoma with a study design involving washout of medications at follow-up, thereby removing the confounding effects of medications. Implantation of a Hydrus Microstent combined with cataract surgery provides a significant reduction in IOP and adjunctive medication use compared with cataract surgery alone.

\section{Performance and Safety of a New $A b$ Interno Gelatin Stent in Refractory Glaucoma at 12 Months $^{7}$}

The XEN ${ }^{\circledR} 45$ Gel Stent (Allergan PLC, Dublin, Ireland) is a $6 \mathrm{~mm}$ gelatin tube with a $45 \mu \mathrm{m}$ inner lumen diameter. A conjunctival peritomy was created during the trial to allow for direct sponge application of mitomycin-C to the scleral bed for 2 minutes. The stent was then implanted into the sub-Tenon's space in ab interno fashion via a clear corneal incision under gonioscopic guidance, followed by conjunctival closure.

This prospective, noncomparative, multicenter study involved 65 patients who underwent implantation with the XEN Gel Stent. Primary performance outcomes included percentage of patients achieving $\geq 20 \%$ IOP reduction from baseline on the same or fewer medications, and mean IOP change from baseline at month 12 .

\section{Key findings}

At 12 months, $76.3 \%$ of patients achieved $\geq 20 \%$ mean IOP reduction from baseline using the same number of or fewer medications. Mean IOP reduction from baseline was $6.4 \pm 1.1 \mathrm{mmHg}$ (95\% confidence interval: -8.7, -4.2). Among 52 patients who did not require additional surgical intervention, mean IOP was reduced from a baseline of $25.1 \pm$ $3.7 \mathrm{mmHg}$ to $15.9 \pm 5.2 \mathrm{mmHg}$. Mean number of medications decreased from a baseline of $3.5 \pm 1.0(n=65)$ to $1.7 \pm 1.5(n=52)$. Postoperative adverse events included transient hypotony (IOP <6 mmHg; $24.6 \%$ ), largely self-limited loss of best-corrected visual acuity $>2$ lines (27.7\%), and needling (32.3\%). One (1.5\%) patient developed device erosion requiring surgical revision. Nine (13.8\%) patients required additional glaucoma surgery.

\section{Study limitations}

This was a nonrandomized, noncomparative study. Investigator masking was not performed. A subset of patients on maximal medical therapy were included in this study as having refractory glaucoma and received this 
procedure as a primary surgery, regardless of whether they had previous glaucoma surgery.

\section{Bottom line}

This pivotal US Food and Drug Administration study of the XEN Gel Stent evaluated a patient population with refractory glaucoma, with the majority having had prior incisional glaucoma surgery. Though the results were encouraging, modifying the technique for implantation as well as mitomycin-C use may allow for this device to be used safely and effectively in a broader patient population.

\section{Gonioscopy-Assisted Transluminal Trabeculotomy, a Novel $\boldsymbol{A} \boldsymbol{b}$ Interno Trabeculotomy ${ }^{8}$}

In this retrospective, non-comparative case series, Grover et al. reported on 85 patients who underwent gonioscopy-assisted transluminal trabeculotomy (GATT). This novel procedure is performed with an $a b$ interno, conjunctival sparing technique. Patients were observed for at least 6 months postoperatively. Main outcome measures included IOP, number of glaucoma medications, visual acuity, and intraoperative and postoperative medications.

\section{Key findings}

Six months postoperatively, 57 patients with POAG exhibited a mean decrease in IOP of $7.7 \mathrm{mmHg}$ (standard deviation [SD], $6.2 \mathrm{mmHg}$ ) and an average reduction in glaucoma medications by 0.9 (SD, 1.3). The secondary glaucoma group of 28 patients exhibited a statistically significant mean decrease in IOP of $17.2 \mathrm{mmHg}$ (SD, $10.8 \mathrm{mmHg}$ ). Patients with secondary glaucoma demonstrated a significant mean decrease in glaucoma medications of $2.2(S D, 1.5)$. Treatment was considered to have failed in $9 \%$ of patients because they required further glaucoma surgery. Lens status or concurrent cataract surgery did not have a statistically significant effect on IOP in eyes that underwent GATT at either 6 or 12 months ( $p>0.35$ ).

\section{Study limitations}

This was a nonrandomized, noncomparative study. There was some variability in the reporting of adverse events, particularly in the documentation of hyphema (layered versus microhyphema).

\section{Bottom line}

With the internal, minimally invasive approach of the GATT procedure, the ability to perform goniotomy without violating and scarring the conjunctiva is ideal. However, this procedure is not for everyone. In a subsequent study of 2-year data, patients with POAG with visual field deficits with a mean deviation of $-15 \mathrm{~dB}$ or worse had a $90 \%$ chance of failure with GATT. Further long-term studies will be useful in defining rates of success and safety.

\section{Conclusion}

The trials reviewed above have provided insight into the clinical management of glaucoma, and have even influenced paradigm shifts in surgical trends. As always, each surgeon must consider the individual patient and his or her individual surgical skill prior to selecting an intervention. Follow-up data from each of the above trials will provide further valuable information. •
1. Gedde SJ, Schiffman JC, Feuer WJ, et al. Treatment outcomes in the tube versus trabeculectomy (TVT) study after five years of follow-up. Am J Ophthalmol. 2012;153:789-803.

2. Gedde SJ, Feuer WJ, Shi W, et al. Treatment Outcomes in the Primary Tube Versus Trabeculectomy study after 1 year of follow-up. Ophthalmology. 2018;125:650-63.

3. Netland PA, Sarkisian SR, Moster MR, et al. Randomized, prospective, comparative trial of EX-PRESS glaucoma filtration device versus trabeculectomy (XVT study). Am J Ophthalmol. 2014;157:433-40.
4. Vold S, Ahmed IIK, Craven ER, et al. Two-year COMPASS trial results: supraciliary microstenting with phacoemulsification in patients with open-angle glaucoma and cataracts. Ophthalmology. 2016;123:2103-12.

5. US Food \& Drug Administration. Potential eye damage from Alcon CyPass Micro-Stent used to treat open-angle glaucoma: FDA safety communication. 2018. Available at: www.fda.gov/ MedicalDevices/Safety/AlertsandNotices/ucm620646.htm Accessed September 14, 2018

6. Pfeiffer N, Garcia-Feijoo J, Fea AM, et al. A randomized trial of a Schlemm's canal microstent with phacoemulsification for reducing intraocular pressure in open-angle glaucoma. Ophthalmology. 2015;122:1283-93.

7. Grover DS, Flynn WJ, Bashford KP, et al. Performance and safety of a new ab interno gelatin stent in refractory glaucoma at 12 months. Am J of Ophthalmol. 2017:183:25-36.

8. Grover DS, Godfrey DG, Smith O, et al. Gonioscopy-assisted transluminal trabeculotomy, ab interno trabeculotomy: technique report and preliminary results. Ophthalmology 2014;121:855-861. 